\title{
G-Protein Coupled Receptor-Evoked Glutamate Exocytosis from Astrocytes: Role of Prostaglandins
}

\author{
Corrado Cali, Jan Lopatar, Francesco Petrelli, Luca Pucci, and Paola Bezzi \\ Department of Fundamental Neurosciences, Faculty of Biology and Medicine, University of Lausanne, \\ rue du Bugnon 9, 1005 Lausanne, Switzerland
}

Correspondence should be addressed to Paola Bezzi; paola.bezzi@unil.ch

Received 4 October 2013; Accepted 16 December 2013; Published 16 January 2014

Academic Editor: Emma Victoria Jones

Copyright (C) 2014 Corrado Cali et al. This is an open access article distributed under the Creative Commons Attribution License, which permits unrestricted use, distribution, and reproduction in any medium, provided the original work is properly cited.

Astrocytes are highly secretory cells, participating in rapid brain communication by releasing glutamate. Recent evidences have suggested that this process is largely mediated by $\mathrm{Ca}^{2+}$-dependent regulated exocytosis of VGLUT-positive vesicles. Here by taking advantage of VGLUT1-pHluorin and TIRF illumination, we characterized mechanisms of glutamate exocytosis evoked by endogenous transmitters (glutamate and ATP), which are known to stimulate $\mathrm{Ca}^{2+}$ elevations in astrocytes. At first we characterized the VGLUT1-pHluorin expressing vesicles and found that VGLUT1-positive vesicles were a specific population of small synaptic-like microvesicles containing glutamate but which do not express VGLUT2. Endogenous mediators evoked a burst of exocytosis through activation of G-protein coupled receptors. Subsequent glutamate exocytosis was reduced by about $80 \%$ upon pharmacological blockade of the prostaglandin-forming enzyme, cyclooxygenase. On the other hand, receptor stimulation was accompanied by extracellular release of prostaglandin $\mathrm{E}_{2}\left(\mathrm{PGE}_{2}\right)$. Interestingly, administration of exogenous $\mathrm{PGE}_{2}$ produced per se rapid, store-dependent burst exocytosis of glutamatergic vesicles in astrocytes. Finally, when $\mathrm{PGE}_{2}$-neutralizing antibody was added to cell medium, transmitter-evoked exocytosis was again significantly reduced (by about 50\%). Overall these data indicate that cyclooxygenase products are responsible for a major component of glutamate exocytosis in astrocytes and that large part of such component is sustained by autocrine/paracrine action of $\mathrm{PGE}_{2}$.

\section{Introduction}

The morphology and the location of astrocytes place them in a unique position to be able to listen and respond to neuronal activity [1-5]. Astrocytes express a wide variety of functional neurotransmitter receptors essential for sensing neuronal activity [6]. Many of these receptors are G-proteincoupled receptors (GPCRs) that, upon activation, stimulate phospholipase $\mathrm{C}$ and form inositol $(1,4,5)$-triphosphate (IP3) which increases the intracellular calcium $\left(\mathrm{Ca}^{2+}\right)$ concentration through the release of $\mathrm{Ca}^{2+}$ from intracellular stores [6]. The intracellular cascade resulting in $\mathrm{Ca}^{2+}$ rise in astrocytes is the main mechanism these cells use to transduce synaptic activity. It is well established that the GPCR- mediated $\mathrm{Ca}^{2+}$ variations in astrocytes can trigger release of chemical substances $[7,8]$ such as excitatory amino acids (D-serine, glutamate) $[2,9,10]$, ATP, and related nucleotides and nucleosides [11-13] or proinflammatory mediators such as eicosanoids (prostaglandins or PG) $[2,14]$ and tumor necrosis factor alpha (TNF $\alpha$; [5, 15-17]). Interestingly, prostaglandin $\mathrm{E}_{2}\left(\mathrm{PGE}_{2}\right)$ and $\mathrm{TNF} \alpha$ have been described to play an important role in the modulation of the regulated secretion of glutamate $[5,15-$ 17]. $\mathrm{PGE}_{2}$ and $\mathrm{TNF} \alpha$ at pathological concentrations appear to exert a potent control on $\mathrm{Ca}^{2+}$-dependent glutamate release from astrocytes $[15,18]$ and therefore could directly influence glial cells potentially resulting in complex changes in the brain network. Thus, when a local inflammatory reaction is triggered in the brain, the increased levels of such proinflammatory mediators can deeply alter the properties of glial network and thus of neuronal network [7]. However, $\mathrm{PGE}_{2}$ and TNF $\alpha$ are also present in the normal brain, albeit at much lower levels than during inflammatory reactions. Constitutive levels of $\mathrm{TNF} \alpha$, in particular, have been implicated in control of the stability of neuronal networks in response to prolonged changes in activity via the phenomenon of synaptic scaling $[19,20]$ and play a role in controlling the strength of 
excitatory synaptic transmission by promoting the insertion of AMPA receptors at the surface $[21,22]$. The involvement of $\mathrm{TNF} \alpha$ in regulating glutamate release from astrocytes during physiological conditions has been found in TNF $\alpha$ - and TNF receptor 1 knockout mice, pointing to a permissive role for the cytokine in the exocytosis of glutamate from astrocytes [17]. Recently, it has been discovered the way how TNF $\alpha$ modulates glutamate release from astrocytes and how this impinges on the astrocytic modulation of synaptic activity [5]. Much less information is available about the mechanism by which PGs can control glutamate release in response to activation of GPCRs $[2,15]$. Here by taking advantage of a construct containing the vesicular glutamate transporter 1 and a $\mathrm{pH}$-sensitive fluorescent marker of fusion (VGLUT1pHluorin) and of total internal reflection fluorescence (TIRF) microscopy, we investigated the role of PGs in the glutamate exocytosis processes in astrocytes. We initially characterized secretory organelles expressing VGLUT1-pHluorin in astrocytes and found that the VGLUT1-pHluorin-expressing vesicles contain glutamate and belong to the family of small synaptic-like microvesicles (SLMVs) and not of other larger secretory organelles (such as dense core granules or lysosomes). Then we found that the exocytosis of such glutamatergic SLMVs, elicited by two endogenous mediators, as diverse as glutamate and ATP, are strongly depressed by pharmacological inhibition of cyclooxygenase (COX). We also provide evidence that $\mathrm{PGE}_{2}$ exerts most of its activity in amplifying exocytosis of glutamate after it is released in the extracellular medium. We conclude that activation of COX pathway should be regarded as a crucial step in the modulation of the GPCR mediated glutamate exocytosis from astrocytes.

\section{Material and Methods}

2.1. Pharmacological Agents, Constructs, and Transfection. All agents (acetylsalicylic acid, indomethacin, prostaglandin E2, adenosine $5^{\prime}$ triphosphate disodium salt (ATP), (+)- $\alpha$ Methyl-4-carboxyphenylglycine (MCPG), adenosine- $3^{\prime}$ phospho- $5^{\prime}$-phosphosulfate (A3P5PS), 2-methylthioadenosine 5 ' diphosphate trisodium salt (2MeSADP), and (S)-3,5dihydroxyphenylglycine hydrate (DHPG)) were from Sigma (St. Louis, USA), unless otherwise indicated. 2-Methyl-6(phenylethynyl)-pyridine (MPEP) and pyridoxalphosphate6-azophenyl-2 ${ }^{\prime}, 4^{\prime}$-disulfonic acid tetrasodium salt (PPADS) are from Tocris Cookson (Bristol, UK). Anti-PGE 2 antibody $\left(\mathrm{AbPGE}_{2}\right)$ was from Cayman Chemical (Liestal, Switzerland); cyclopiazonic acid (CPA, CalBiochem, USA); Alexa 568conjugated transferrin (Life Technologies, USA); plasmid containing the VGLUT1-pHluorin constructs was prepared as previously described [24]. The plasmid ( $0.5 \mu \mathrm{g}$ for single transfection experiments) was transfected into primary rat cortical astrocytes cultures with FuGene6 $(3 \mu \mathrm{L}$, Roche Diagnostics, Switzerland).

2.2. Astrocyte Cultures for Imaging Experiments. Astrocyte cultures containing $>99 \%$ GFAP-positive cells ( $\leq 8 \%$ of which were positive for the neural precursor marker LeX) were obtained from newborn rats. They were prepared as described [9], plated $\left(2.5 \times 10^{4}\right.$ cells $)$ on glass coverslip, and transfected 6-8-days later with VGLUT1-pHluorin. From 2 to 5 days after transfection, and coverslips were mounted in the open laminar flow perfusion incubator at $37^{\circ} \mathrm{C}$ (Harvard Apparatus, USA) on the stage of a Zeiss Axiovert 200 fluorescence inverted microscope modified for TIRF experiments (Visitron System, Germany). The experimental chamber $(250 \mu \mathrm{L}$ volume) was perfused at a rate of $1-1.5 \mathrm{~mL} / \mathrm{min}$. The stimulus (DHPG, ATP, tACPD/AMPA, PGE 2 , 2MeSADP) was applied rapidly ( $2 \mathrm{sec}$ ) via a software-controlled microperfusion faststep device $(100 \mu \mathrm{L} / \mathrm{min}$, Warner Instruments Corp., USA). Cells were perfused at $37^{\circ} \mathrm{C}$ in a HEPES-KRH buffer containing (in mM) $\mathrm{NaCl} 120, \mathrm{KCl} 3.1, \mathrm{MgCl}_{2} 2, \mathrm{CaCl}_{2} 1.8, \mathrm{NaH}_{2} \mathrm{PO}_{4}$ 1.25, HEPES-Na 25 (buffered to $\mathrm{pH} 7.4$ ), and glucose 4 . In experiments with CPA, PPADS, A3P5PS, MCPG, MPEP, INDO, ASA, and $\mathrm{AbPGE}_{2}$ the drugs were diluted in HEPES$\mathrm{KRH}$ and incubated for $15 \mathrm{~min}$ before the application of the stimulus.

2.3. Optical Imaging. TIRF illumination (TIRFi) was used for our experiments. The expanded beam of a 488/568 nm argon/krypton multiline laser (20 milliwatts, Laserphysics, Germany) passed through an AOTF laser wavelength selector (VisiTech International, UK) synchronized with a SNAP-HQ CCD camera (Roper Scientific, Germany) under Metafluor software (Universal Imaging, USA) control and was introduced to the coverslip from the high numerical aperture objective lens (Zeiss $\alpha$-plan FLUAR 100X). Light entered the coverslip and underwent total internal reflection at the glasscell interface. In our experimental conditions, penetration depth of TIRFi was calculated to be about $90 \mathrm{~nm}[17,25]$. In single-wavelength TIRFi experiments $(488 \mathrm{~nm})$ the laser beam was filtered via the Zeiss filter set 10 and images were acquired at $20-40 \mathrm{~Hz}$ (Zeiss, Switzerland). In dualwavelength TIRF illumination $(488 / 568 \mathrm{~nm})$, laser beams were combined by a dichroic mirror from the Zeiss filter 24 at $20-40 \mathrm{~Hz}$. The pixel size was $126 \mathrm{~nm}$ (at binning 2).

2.4. Image Analysis. Video images, digitized with MetaFluor, were analyzed with MetaMorph software (Universal Imaging, USA). The fusion events of VGLUT-pHluorin positive vesicles were manually selected and counted in areas of 6000 pixels on cell surface as already reported [9, 26, 27]. A fluorescent spot was counted as "fusion event" when the pHluorin fluorescence signal of a single SLMV increased over basal by $\geq 4$-fold.

2.5. Immunocytochemistry. Astrocytes were plated on glass coverslips coated with $2 \mathrm{mg} / \mathrm{mL}$ poly-L-lysine and $33 \mathrm{mg} / \mathrm{mL}$ laminin and cultured for 2 days. The cells were rinsed with phosphate-buffered saline (PBS) and fixed in ice-cold methanol for $15 \mathrm{~min}$. After two washes in ice-cold PBS, the coverslips were incubated for $10 \mathrm{~min}$ with PBS containing $0.5 \%$ saponin (PBS-S) and rinsed three times for $5 \mathrm{~min}$ with PBS. They were then incubated for $30 \mathrm{~min}$ in PBS$S$ containing $1 \%$ bovine serum albumin (BSA) and for 1 hour at room temperature in the presence of the primary 
antibodies diluted in PBS-S plus 1\% BSA. The cells were rinsed with PBS, incubated 1 hour with the secondary antibody, and mounted for confocal microscopy (Leica SP5 AOBS Confocal Microscope). Primary antibodies were rabbit GFP (1:500, Chemicon), mouse VGLUT1 (1:500, Chemicon), VGLUT2 (1:2000, gift Robert Edwards, USA), VAMP3, (1:1000, Synaptic System), glutamate (1:3000, gift Vidar Gundersen, Oslo), VAMP2 (1:1000, Synaptic System), phogrin (1: 500, gift Romano Regazzi, Lausanne), LAMP1 (1:100, Calbiochem), EAA1 (1:100, BD Transduction Lab), and $\mathrm{Tf}$ receptor $(1: 100$, Invitrogen). Secondary antibodies were Cy3 or FITC-conjugated (1:200, Molecular Probes).

2.6. Monitoring of Extracellular $P G E_{2}$ Formation. Extracellular $\mathrm{PGE}_{2}$ was measured using a sensitive EIA kit (Prostaglandin E2 EIA kit-Monoclonal, Cayman Chemical Company, Ann Arbor). Cultured astrocytes plated on Petri dishes were washed twice with a $\mathrm{KRH}$ buffer containing (in $\mathrm{mM}$ ) $\mathrm{NaCl} 120, \mathrm{KCl} 3.1, \mathrm{MgCl}_{2} 2, \mathrm{CaCl}_{2} 1.8, \mathrm{NaH}_{2} \mathrm{PO}_{4}$ 1.25, and HEPES-Na 25 (buffered to $\mathrm{pH} 7.4$ ). Subsequently they were stimulated ( $3 \mathrm{~min}$ ) with agents dissolved in the same buffer also containing an antiPGE ${ }_{2}$ antibody $\left(\mathrm{AbPGE}_{2}\right.$, Cayman Chemical) at concentration buffering $>1000 \mathrm{pg} / \mathrm{mL} \mathrm{PGE}_{2}$. At the end of stimulations, the extracellular medium was rapidly collected, lyophilized and kept at $-80^{\circ} \mathrm{C}$ until performing the EIA assay according to instructions.

2.7. Statistical Analysis. The experiments were analyzed using the SAS statistical package (SAS Inc., Cary, NC, USA). Statistical differences were tested by $t$-test and $P$ values of $0.01^{* *}$ or $0.05^{*}$.

\section{Results}

Glutamatergic vesicles in astrocytes have been highlighted by transfecting cultured cells with the fluorescent construct VGLUT1-pHluorin, consisting of vesicular glutamate transporter 1 (VGLUT1) fused to a $\mathrm{pH}$ sensitive GFP mutant (pHluorin; [28]). Overexpression of VGLUT1-pHluorin in primary cortical astrocytes produced a punctate pattern of fluorescence (Figure 1). Astrocytes, similar to specialized secretory cells, contain three types of secretory organelles, the glutamate containing synaptic-like microvesicles (SLMVs) $[9,29,30]$, the peptide containing large dense-core granules (LDCGs; [31, 32]), and the lysosomes [11-13]. These secretory organelles can be distinguished by immunocytochemistry and confocal analysis in primary cultured cells by using antibodies directed against endogenous markers [33]. In order to characterize which population of secretory organelles expressed VGLUT1-pHluorin, we performed a series of immunolabeling and confocal analysis. The VGLUT1-expressing vesicles were well colocalized with antiVGLUT1 antibody (92 $\pm 3.5 \%$ for $n=7$ cells, Figure 1(a)) but not with anti-VGLUT2 antibody $(5 \pm 2.7 \%$ for $n=5$ cells, Figure 1(b)), indicating that VGLUT1-pHluorin is expressed on a particular set of intracellular glutamatergic vesicles. The VGLUT1-expressing vesicles showed a large co-localization with markers of SLMVs [9] such as VAMP3 (or cellubrevin,
$94 \pm 5.5 \%$ for $n=5$ cells, Figure $1(\mathrm{c}))$ and glutamate $(92 \pm 6.2 \%$ for $n=5$ cells, Figure $1(\mathrm{~d}))$. Interestingly, the VGLUT1associated vesicles showed only a small co-localization with endogenous VAMP2 (17 $\pm 2 \%$ for $n=5$ cells, Figure $1(\mathrm{e}))$ and with markers of other secretory organelles such as LDCGs (phogrin, $2.3 \pm 1.7 \%$ for $n=5$ cells, Figure 1(f)) or lysosomes, (LAMP1, $3 \pm 1.2 \%$ for $n=5$ cells, Figure $1(\mathrm{~g})$ ). We also checked the co-localization of VGLUT1-positive vesicles with other lysosomal markers, including early endosomes with EAA1 $(13 \pm 7.3 \%$ for $n=5$ cells, Figure 1(h)) [34] and the recycling endosomes with transferrin receptor (18 $\pm 7 \%$ for $n=5$ cells, Figure 1(i), [35]). Early endosomes and recycling endosomes represent two distinct populations of endosomes that significantly colocalized with VGLUT1-pHluorin (colocalization about 20\%). In order to clarify whether the organelles double positive for VGLUT1-pHluorin and the marker of early endosomes (EAA1) represent a population different from SLMVs, we estimated the average fluorescence profiles (radial sweep; [23]) of fluorescent vesicles from the double immunofluorescent labeling experiments shown in Figure 1(h). For analysis, we compared the half maximum values (FWHM) of the curve obtained from isolated green fluorescent dots representing VGLUT1-pHluorin which colocalize with EAAl with the corresponding value of radial sweep curves of fluorescent beads of different diameters (40 $\mathrm{nm}$ and $200 \mathrm{~nm}$ ). We found that the VGLUT1-pHluorin dots colocalized with EAA1 had a FWHM value similar to that of $200 \mathrm{~nm}$ beads $(490 \pm 5 \mathrm{~nm}, n=20 ; 506 \pm 6 \mathrm{~nm}$, $n=20$, resp., Figures 2(a) and 2(b)). Conversely, the green fluorescent dots of VGLUT1-pHluorin that do not colocalize with EAA1 had FWHM comparable to that of fluorescent beads of $40 \mathrm{~nm}$ of diameter ( $349 \pm 7 \mathrm{~nm}$ and $361 \pm 6 \mathrm{~nm}$, resp., $n=20$ for each, Figures 2(c) and 2(d)). Thus, the organelles double positive for pHluorin and EAAl were clearly a different population of organelles from those expressing only VGLUT1-pHluorin and most probably represent part of VGLUT1-pHluorin-positive organelles undergoing endosomal/lysosomal recycling pathway. In a parallel set of experiments, in order to rigorously determine whether population of VGLUT1-pHluorin positive vesicles also positive for marker of recycling endosomes was able to undergo regulated exocytosis, we monitored the exocytosis processes evoked by an agonist of group I metabotropic glutamate receptors (mGluR), dihydroxyphenylglycine (DHPG) [9, 29]. Primary astrocytes transfected with VGLUT1-pHluorin and preincubated with a specific marker of recycling endosomes (Alexa 568-conjugated transferrin, [35]) have been challenged with DHPG $(100 \mu \mathrm{M})$ for 2 seconds (s). The VGLUT1-pHluorinand the Alexa568-positive vesicles have been followed in real time with the dual wavelength TIRF experiments $(488 \mathrm{~nm}$ and $568 \mathrm{~nm}$ laser TIRF). Two seconds of DHPG application evoked a burst of exocytosis of VGLUT1-pHluorin vesicles as previously reported (Figure 2(e); [9]) and only $16 \%$ of fusion events of VGLUT1-pHluorin/Alexa-568 double positive vesicles (Figure 2(f)). Overall, these data showed that VGLUT1pHluorin can be used as a surrogate marker for glutamatergic SLMVs in astrocytes.

To analyze the role of prostaglandins (PGs) in the DHPGevoked exocytosis of glutamatergic vesicles in astrocytes, 

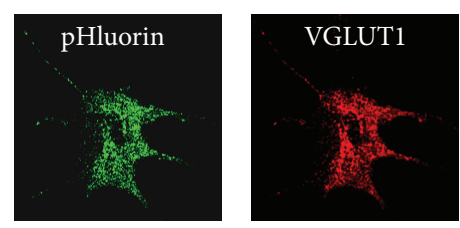

(a)
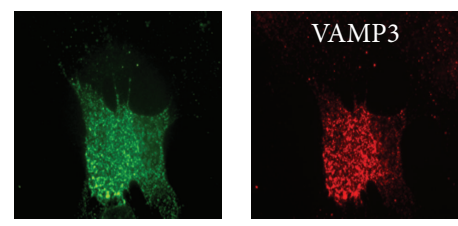

(c)
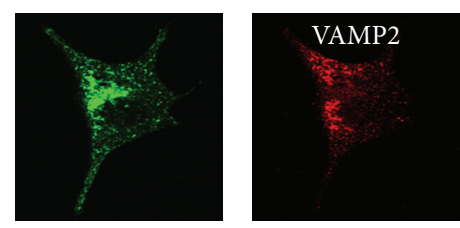

(e)
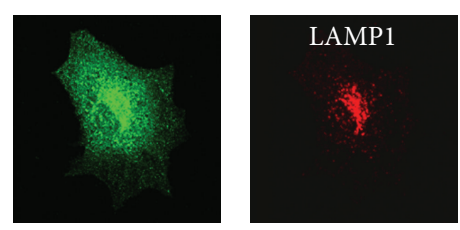

(g)
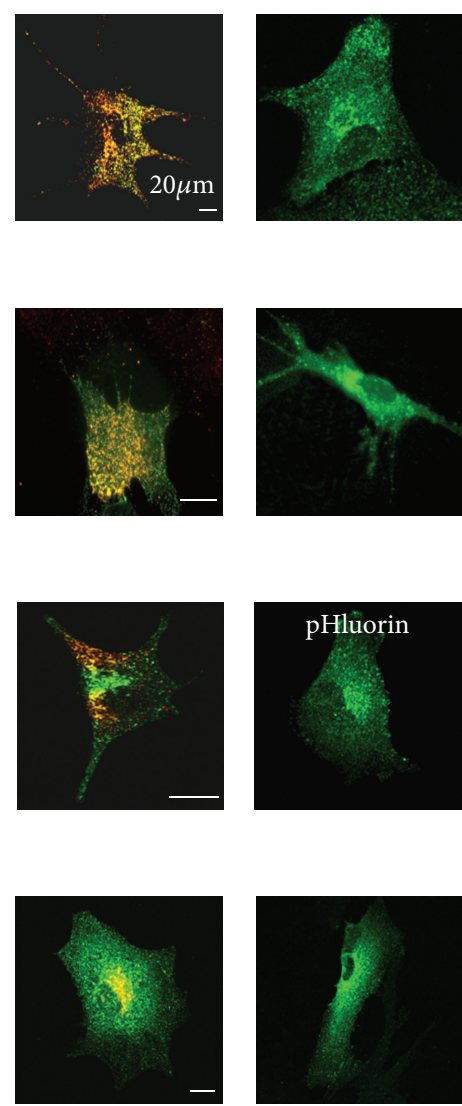

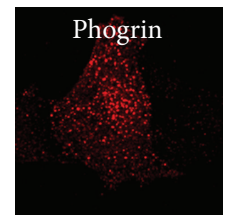

(f)

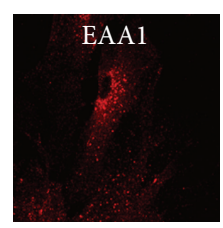

(h)

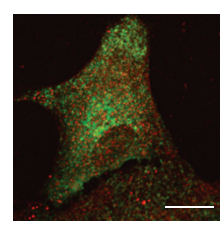

(b)
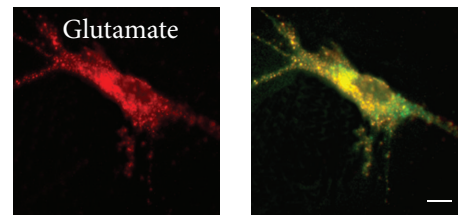

(d)
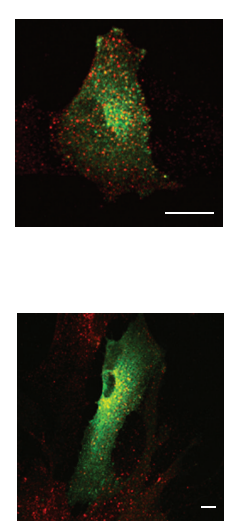
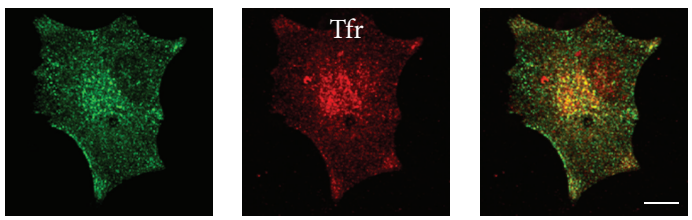

(i)

FIGURE 1: VGLUT1-pHluorin is mainly expressed on a specific population of glutamatergic synaptic like microvesicles. In the figure the left panels (in green) show astrocytes transfected with VGLUT1-pHluorin construct revealed by rabbit antibody against GFP. The middle panels (in red) show the markers of the intracellular secretory organelles, revealed by mouse antibodies against specific markers of $((\mathrm{a})-(\mathrm{e}))$ synaptic like microvesicles ((a) VGLUT1, (b) VGLUT2, (c) VAMP3, (d) glutamate, (e) VAMP2), of (f) dense core granules (phogrin), of (g) late endosomes, multivesicular bodies and lysosomes (LAMP1), of (h) early endosomes (EAA1), and of (i) recycling endosomes (transferrin receptor, Tfr). The right panels show the merged images. Bars: $20 \mu \mathrm{m}$.

we started by monitoring single exocytic events of VGLUT1pHluorin-associated vesicles (Figures 3(a) and 3(b); [9]), evoked by two distinct protocols of receptor stimulation. When either purinergic receptor or glutamatergic receptor agonists were locally administrated (ATP, $100 \mu \mathrm{M}$, or coapplication of t-ACPD and AMPA each at $50 \mu \mathrm{M})$, rapid burst of exocytosis was elicited (Figures 3(c) and $3(\mathrm{e})$ ), suggesting that the two stimulation protocols shared similar excitation-secretion coupling mechanism. The nature of the receptors activated by the three protocols of stimulation was then investigated by pharmacological agents with known selectivity. The response to ATP was abolished by pretreatment with PPADS $(-86 \%, 100 \mu \mathrm{M})$, an agonist of most $\mathrm{P} 2$ purinergic receptors, as well as with A3P5PS (-83\%, $100 \mu \mathrm{M}$ ), a selective $\mathrm{P}_{2} \mathrm{Y}_{1}$ antagonist (Figure 3(d); [36]).

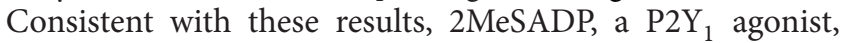
potently stimulated glutamate exocytosis (data not shown), (see Supplementary Figure 1; in Supplementary Material available online at http://dx.doi.org/10.1155/2014/254574 [5, 17]), suggesting that $\mathrm{P} 2 \mathrm{Y}_{1}$ receptors are the predominant mediators of the glutamate exocytosis action of ATP. The presence of $\mathrm{P}_{2} \mathrm{Y}_{1}$ receptors in astrocytes and their role in $\mathrm{Ca}^{2+}$ signaling pathway leading to modulation of synaptic activity have recently been reported [5,37]. As for glutamate, it has been established that the potent glutamate releasing effect of $\mathrm{t}-\mathrm{ACPD}+\mathrm{AMPA}$ in astrocytes mainly depends on the 


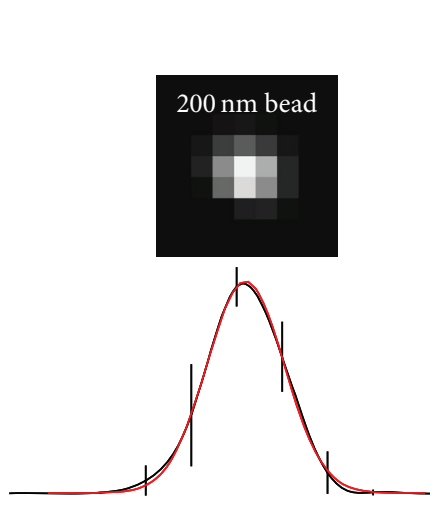

$\mathrm{FWHM}=506 \pm 6 \mathrm{~nm}$

(a)

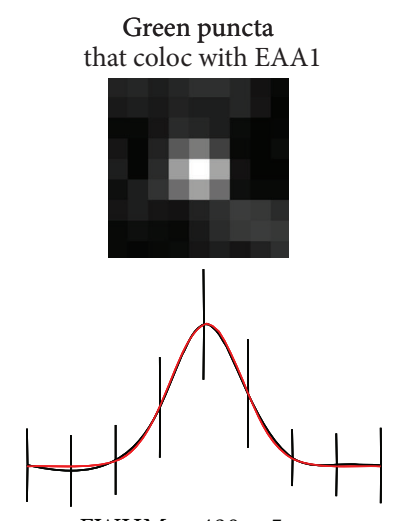

$\mathrm{FWHM}=490 \pm 5 \mathrm{~nm}$

(b)

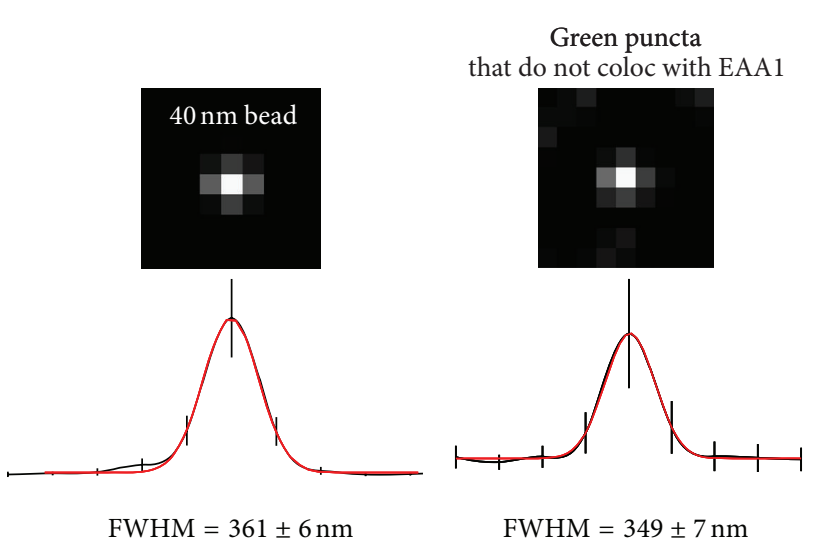

(c)

(d)

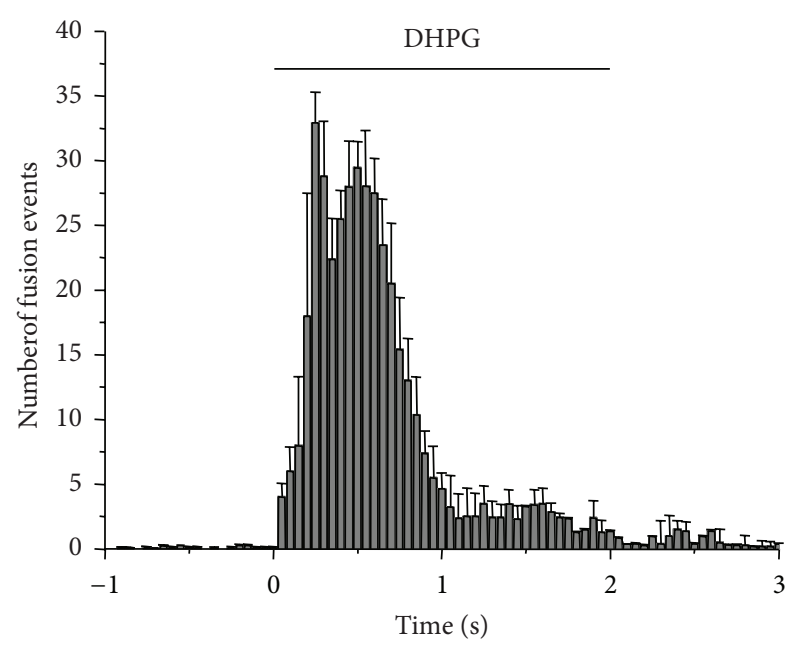

(e)

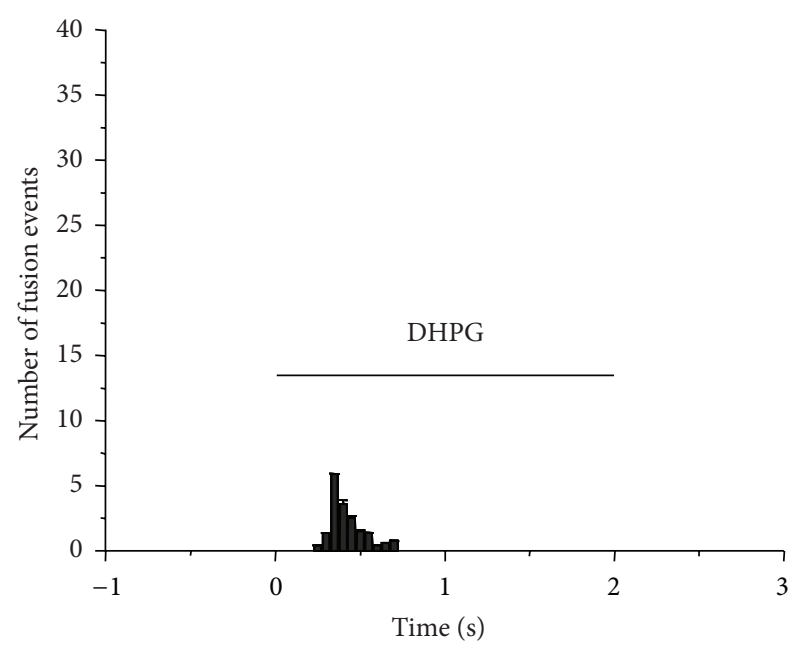

(f)

FIGURE 2: Analysis of VGLUT1-pHluorin vesicles that colocalize with markers of early or recycling endosomes. (a)-(d) Estimation of the size of vesicles expressing VGLUT1-pHluorin. Analysis of individual vesicle was performed in confocal images of VGLUT1-pHluorin-expressing astrocytes by plotting fluorescence intensity of pHluorin spots against distance from the centre of the spot (black curve \pm SD). Such an analysis provided an estimation of the average fluorescence profile otherwise called "radial sweep" [23]. The fluorescence intensity values obtained from the radial sweep were well fitted by a one-dimensional Gaussian function (red curve). Such a curve represents the average radial sweep value obtained from 20 vesicles. Note that the half maximum value of pHluorin-expressing vesicle positive for EAA1 ((b), marker of early endosomes, $490 \pm 5 \mathrm{~nm})$ is similar to that of $200 \mathrm{~nm}$ fluorescent beads ((a), $506 \pm 6 \mathrm{~nm})$ and the half maximum value of pHluorin-expressing vesicle that do not express EAA1 ((d), $349 \pm 7 \mathrm{~nm}$ ) is similar to that of $40 \mathrm{~nm}$ fluorescent beads ((c), $361 \pm 6 \mathrm{~nm})$. (e), (f) Temporal distribution of VGLUT1-pHluorin and Alexa-Tf 568 fusion events evoked by DHPG application. (e) Each individual histogram represents the number (mean \pm SD) of fusion events detected from VGLUT1-pHluorin vesicles in a 50 ms-long frame $(n=5$ cells). (f) Fusion events (mean \pm SD) detected from VGLUT1-pHluorin and Alexa-Tf568 double positive vesicles in the same cells as in (e). Each histogram represents the number of fusion events detected in a $50 \mathrm{~ms}$-long frame $(n=5$ cells $)$.

simultaneous activation of group I mGluRs and ionotropic receptors of the AMPA-preferring subtype [2]. Here, we confirm that the response to $\mathrm{t}-\mathrm{ACPD}+\mathrm{AMPA}$ (each at $50 \mu \mathrm{M}$ ) is reduced to less than $40 \%$ by administration of MCPG $(-78 \%, 500 \mu \mathrm{M})$, a nonselective mGluR antagonist, and by MPEP $(-82 \%, 200 \mathrm{nM})$, a specific antagonist selective for mGluR5 (Figure 3(f)). On the whole, pharmacological profile identified mGluR5 as the metabotropic receptor subtype that is implicated in the glutamate release response to glutamatergic stimulation. Consistent with these results, DHPG, an agonist of the group I of mGluR, evoked glutamate exocytosis in astrocytes $[9,29]$. The two receptors here identified as mediators of the exocytosis of glutamatergic vesicles in astrocytes belong to the $\mathrm{G}$ protein-coupled family, which are known to be expressed in astrocytes and to release $\mathrm{Ca}^{2+}$ from internal stores via IP3 pathway [38].

Glutamatergic stimulation of astrocytes is known to promote rapid, phospholipase A2-dependent activation of the arachidonic acid cascade [2,39]. Pharmacological inhibition of the different eicosanoid-forming pathways indicates that cyclooxygenase (COX) but not other arachidonate metabolic enzymes is involved in the mechanism leading to glutamate release $[2,15,17]$. COX is an enzyme that is responsible for the formation of prostanoids [40]. The three main groups 


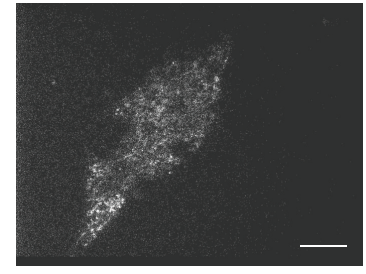

(a)

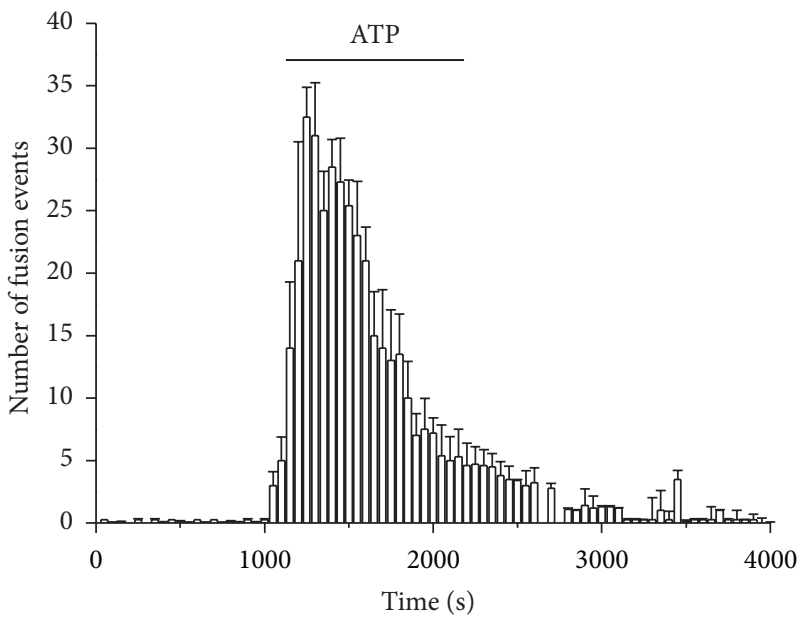

(c)

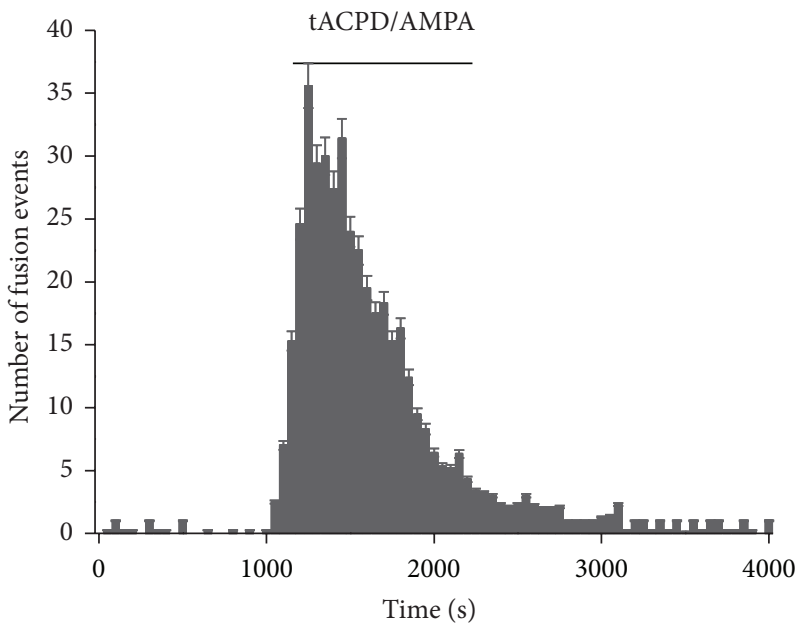

(e)

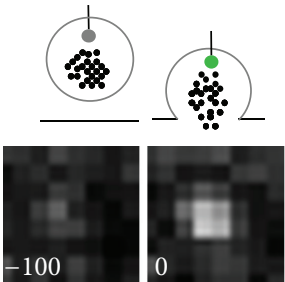

VGLUT-pHluorin<smiles>C1CO1</smiles>
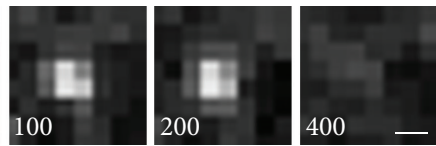

(b)

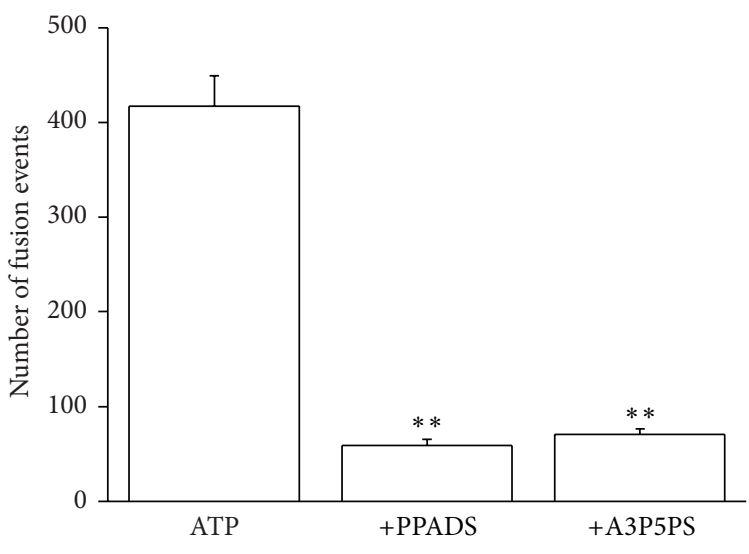

(d)

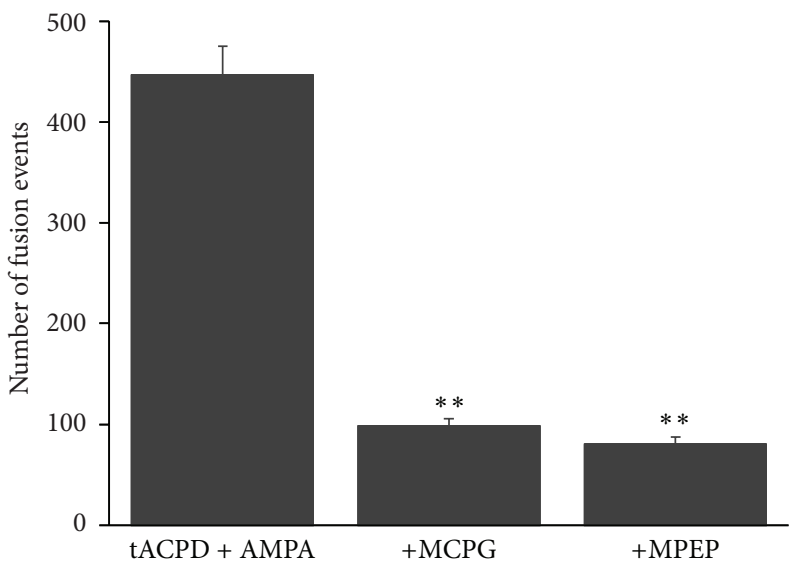

(f)

FIGURE 3: Pharmacological characterization of the receptor subtypes mediating exocytosis of VGLUT1-pHluorin positive vesicles in response to ATP and glutamate agonists. (a) TIRF image showing an astrocyte transfected with VGLUT1-pHluorin. Bar $20 \mathrm{~nm}$. (b) Stereotyped sequence of pHluorin destaining reveals exocytosis of a VGLUT1-pHluorin positive vesicle. The sequential gray scale micrographs represent the fate of pHluorin before $(-100 \mathrm{~ms})$ and during $(100,200,400 \mathrm{~ms})$ the fusion event. Bars: $380 \mathrm{~nm}$. The scheme shows the behaviour of pHluorin before and after fusion event. Note that the color code for the pHluorin fluorescence signal is gray when the signal is off and green when it is on. (c), (d) P2Y receptors mediate the ATP-evoked exocytosis. (c) Temporal distribution of fusion events evoked by ATP (100 $\mu \mathrm{M})$. (d) Histograms represent the total number of fusion events evoked by ATP $(417.14 \pm 32.4)$ that is strongly inhibited in the presence of the P2

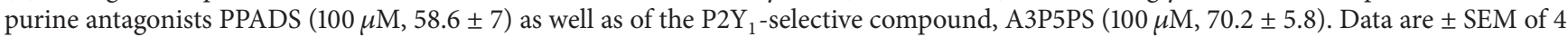
cells. (e), (f) mGluR5 mediates the response to t-ACPD, in the presence of AMPA. (e) Temporal distribution of fusion events evoked by $50 \mu \mathrm{M}$ $\mathrm{t}-\mathrm{ACPD}+50 \mu \mathrm{M}$ AMPA. (f) Histograms represent the total number of fusion events evoked by t-ACPD+AMPA (447.1 \pm 28.7$)$ that is strongly inhibited in the presence of the mGluR antagonists, including the subtype-nonselective MCPG (500 $\mu \mathrm{M}, 98.3 \pm 7.4)$ and the mGluR5-selective MPEP $(200 \mathrm{nM}, 80.1 \pm 7)$. Data are \pm SEM of 4 cells. Statistical significance of inhibition with receptor antagonists was calculated using $t$-test $\left({ }^{* *} P<0.01\right)$. 


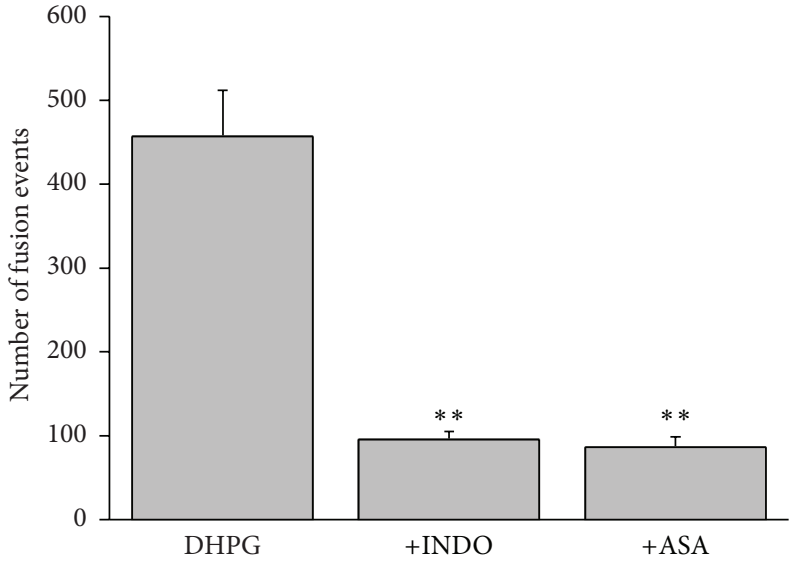

(a)

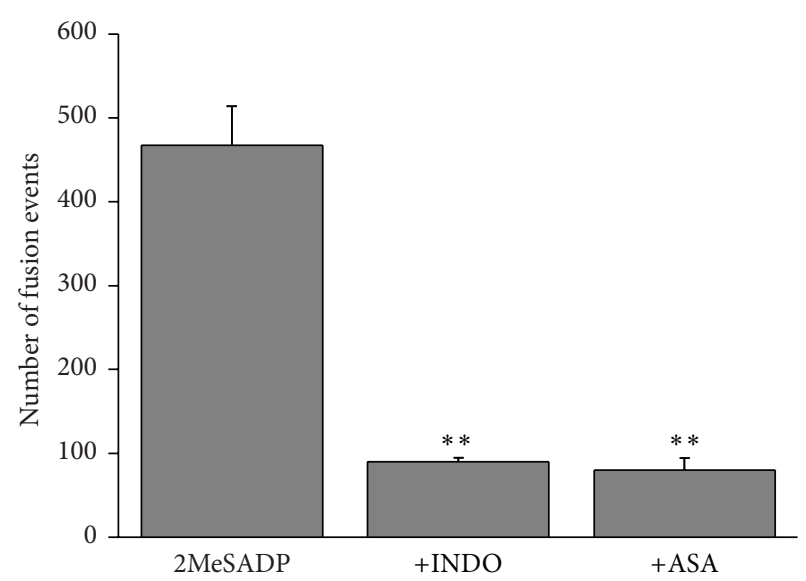

(b)

FIGURE 4: COX blockers strongly inhibit the exocytosis of glutamate evoked by activation of group I mGluR and of purinergic $\mathrm{P}_{2} \mathrm{Y}_{1}$ receptor. (a), (b) Quantitative histograms represent the total number of fusion events evoked by either DHPG $(100 \mu \mathrm{M}, 456.7 \pm 54.8)$ or $2 \mathrm{MeSADP}$ $(20 \mu \mathrm{M}, 467.6 \pm 46.8)$ in the presence of COX blockers, INDO $(1 \mu \mathrm{M} ; 94.9 \pm 9.6,88.8 \pm 5.4$, resp. $)$ or ASA $(10 \mu \mathrm{M}, 86.4 \pm 11.7,79.5 \pm 14.4$, resp.). Data are \pm SEM of 4 cells. Statistical significance of inhibition with receptor antagonists was calculated using $t$-test $\left({ }^{* *} P<0.01\right)$.

of prostanoids (prostaglandins, prostacyclins, and thromboxanes) are each involved in the inflammatory response but prostaglandins (PGs) can control release of glutamate from astrocytes. We studied the involvement of PGs in the DHPGevoked exocytosis of glutamatergic SLMVs by preincubating cells with two COX inhibitors, indomethacin (INDO, $1 \mu \mathrm{M}$ ) and aspirin (ASA, $10 \mu \mathrm{M}$ ). We found that the two antiinflammatory drugs decreased by about $80 \%$ the releasing effect of DHPG and of 2MeSADP (Figures 4(a) and 4(b)). This evidence is consistent with a scenario in which the excitation-secretion pathway leading to glutamate exocytosis from astrocytes is controlled, at some level, by the COX pathway.

In light of the above results, we wanted to examine the mechanism by which COX inhibitors decreased glutamate exocytosis in astrocytes. It is well known that a COX product, prostaglandin $\mathrm{E}_{2}\left(\mathrm{PGE}_{2}\right)$, is formed and released in extracellular space after activation of mGluRs [2] and that it causes by itself intracellular $\mathrm{Ca}^{2+}$ elevations leading to glutamate release in astrocytes $[2,14]$. Interestingly, we also found that the time course analysis of $\mathrm{PGE}_{2}$ accumulation in response to activation of glutamatergic or purinergic receptors was almost maximal within the first 3 seconds of stimulation (Figure 5(a); $[2,17])$. Therefore, the kinetics of the $\mathrm{PGE}_{2}$ release is fully compatible with a potential role of this COX metabolite in rapid cell signaling. We wanted to investigate the effect of $\mathrm{PGE}_{2}$ on the intracellular pathways leading to exocytic burst of glutamatergic SLMVs. We found that administration of $\mathrm{PGE}_{2}(50 \mu \mathrm{M})$ to astrocytes caused a rapid burst of exocytosis that did not depend on $\mathrm{Ca}^{2+}$ influx from outside of the cells but on $\mathrm{Ca}^{2+}$ release from internal store (Figure 5(b)). In fact incubation with cyclopiazonic acid $(1 \mu \mathrm{M})$, which causes depletion of $\mathrm{Ca}^{2+}$ from internal stores by blocking SERCA, abolished the response to $\mathrm{PGE}_{2}$ (Figure 5(b) inset). Since $\mathrm{PGE}_{2}$ is released upon receptor activation and promotes per se $\mathrm{Ca}^{2+}$ elevations and glutamate release, we specifically investigated whether extracellular $\mathrm{PGE}_{2}$ contributes to the physiological response of astrocytes to glutamate exocytosis. We blocked extracellular $\mathrm{PGE}_{2}$ with a specific antibody $\left(\mathrm{AbPGE}_{2}\right)$. Figure $5(\mathrm{~d})$ shows that when $\mathrm{AbPGE}_{2}$ was present in the bath, a condition in which $\mathrm{PGE}_{2}$ is rapidly and efficiently sequestered $\left(\mathrm{AbPGE}_{2}\right.$ buffering capacity is $>1000 \mathrm{pg} / \mathrm{mL} \mathrm{PGE}_{2}$ ), DHPG- evoked exocytosis of glutamatergic SLMVs was significantly reduced $(-43 \pm 12 \%$, $n=6$ cells). Similar results were obtained for 2MeSADP (Supplementary Figure 1(b); $-51 \pm 14 \%, n=4$ cells, resp.). Interestingly, the action of $\mathrm{AbPGE}_{2}$ was specific and could not be reproduced by the boiled protein (not shown). Therefore, the whole body of evidence suggests that extracellular $\mathrm{PGE}_{2}$ accounts for a significant component of mGluR5- and P2 $\mathrm{Y}_{1}$ dependent exocytosis of glutamatergic SLMVs in astrocytes.

\section{Discussion}

Astrocytes play an important role in the integration of rapid chemical signaling in the brain [41]. They function as signal integrators, since they generate outputs with variable timing in response to particular signals received from surrounding neuronal cells to communicate with the same neurons and/or with other cellular components of the brain circuits. A crucial element that facilitates the integrating functions of astrocytes is the regulated exocytosis of chemical substances $[9,29,42-44]$. By this process, astrocytes exert modulatory influences on neighboring cells and are thought to participate in the control of synaptic circuits and cerebral blood flow $[45,46]$. Exocytosis is an evolutionary trait of eukaryotic cells that leads in a given secretory cell to a release of chemical content by a fast mechanism into the extracellular space and thus to communication with neighboring cells. In neurons, exocytosis represents one of the fastest biological events known. Similar to neurons or neurosecretory cells, astrocytes express at least three different secretory organelles: 


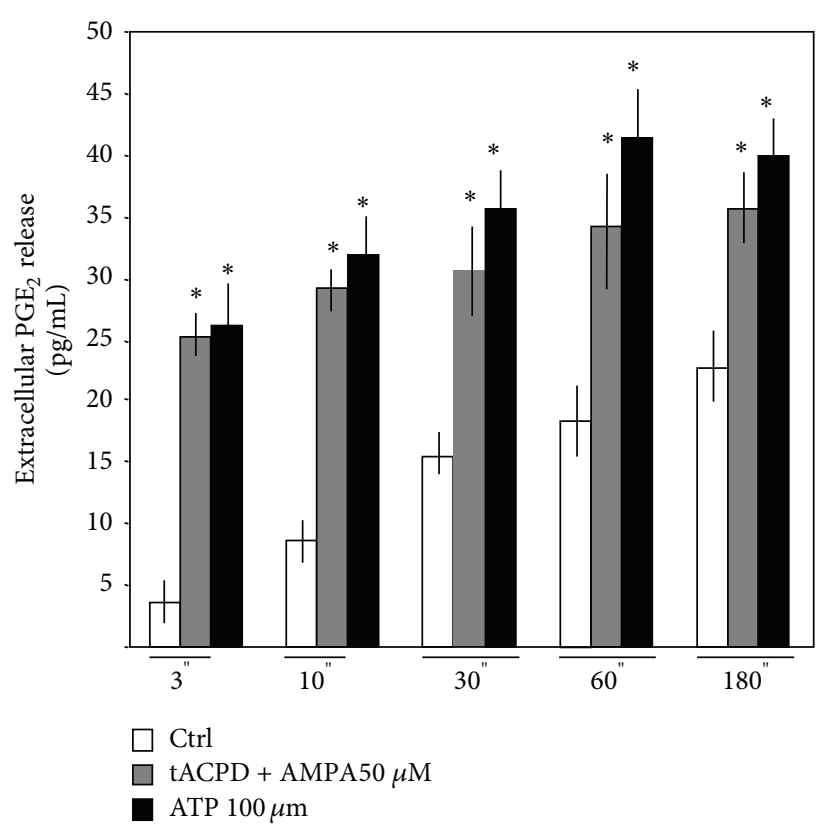

(a)

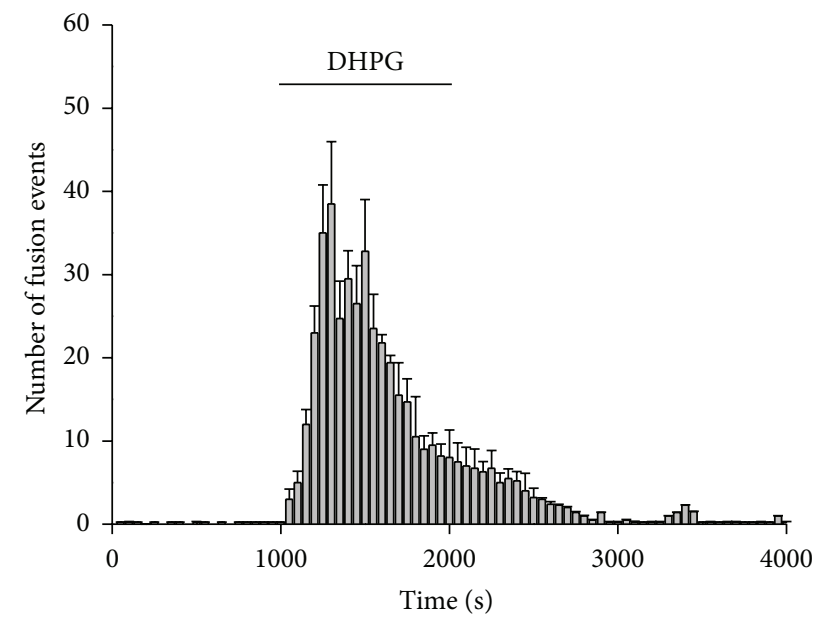

(c)

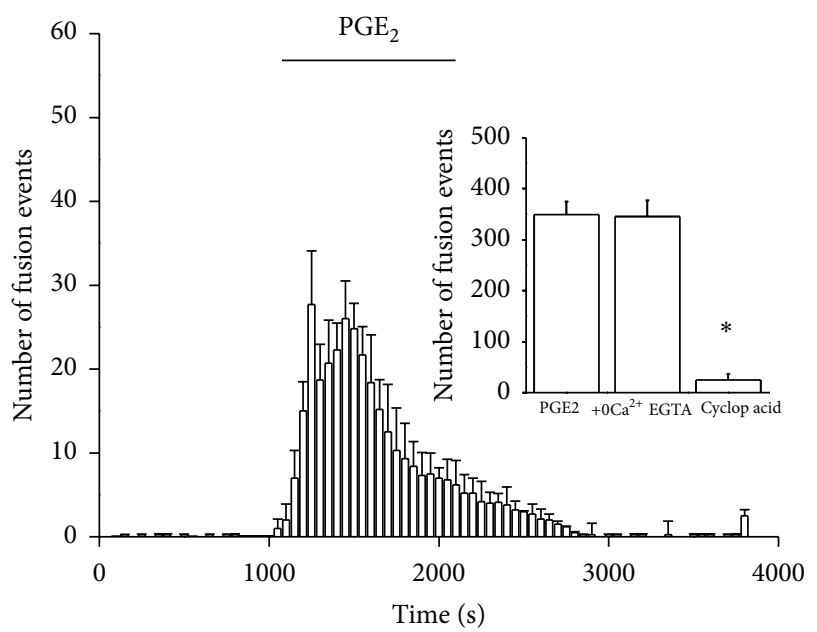

(b)

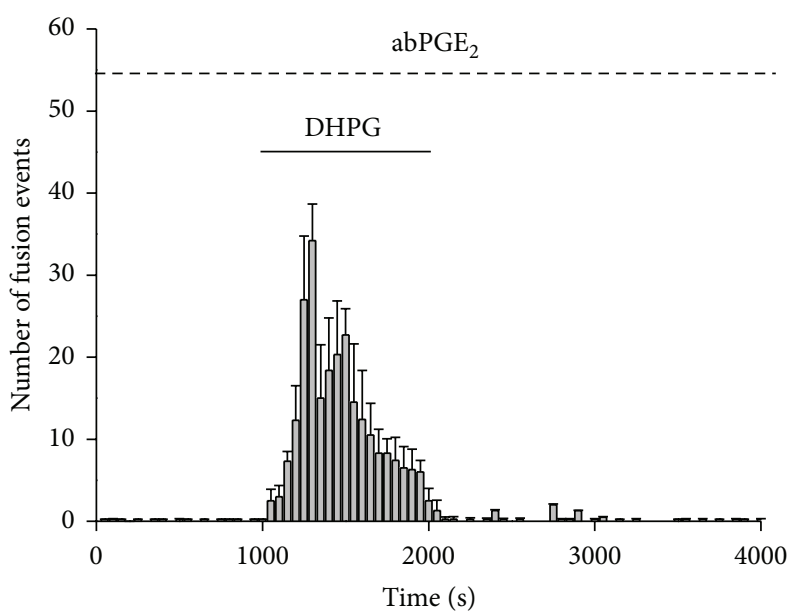

(d)

FIGURE 5: Extracellular $\mathrm{PGE}_{2}$ : accumulation in response to various stimuli and effects on exocytosis of glutamatergic vesicles. (a). Extracellular accumulation of $\mathrm{PGE}_{2}$ (expressed as $\mathrm{pg} / \mathrm{mL}$ ) in response to 3 min stimulation with either t-ACPD+ AMPA (each at $\left.50 \mu \mathrm{M}\right)$ or ATP $(100 \mu \mathrm{M})$. Each point represents the average \pm SEM of two experiments in triplicate with each stimulus. (b) Temporal distribution of fusion events evoked by $\mathrm{PGE}_{2}(50 \mu \mathrm{M})$. Inset histograms represent the total number of fusion events evoked by $\mathrm{PGE}_{2}(349 \pm 26)$ in the presence of $0 \mathrm{mM}$ $\mathrm{Ca}^{2+}$ and $5 \mathrm{mM}$ of EGTA $(345 \pm 32)$ or cyclopiazonic acid $(\mathrm{CPA}, 10 \mu \mathrm{M}, 25 \pm 12)$. (c) Temporal distribution of fusion events evoked by DHPG $(100 \mu \mathrm{M})$. (d) Inhibitory effect of $\mathrm{AbPGE}_{2}$ (buffering capacity $>1000 \mathrm{pg} / \mathrm{mL} \mathrm{PGE}_{2}$ ) on exocytosis of glutamatergic vesicles evoked by DHPG $(100 \mu \mathrm{M})$. Histograms represent temporal distribution of fusion events evoked by DHPG in the presence of $\mathrm{AbPGE}_{2}$. Statistical significance was calculated using $t$-test $\left({ }^{*} P<0.05\right)$.

the small synaptic like microvesicles (SLMVs) [29, 30, 47], the large dense core granules (LDCGs) [31, 32, 48] which store and release distinct cargo, and lysosomes $[49,50]$. In neurons and specialized secretory cells, these organelles have specialized physiological functions, are typically found in different regions of the cell and are regulated by different intracellular signaling pathways of calcium. Interestingly, in our immunolabeling and confocal analysis performed in cultured astrocytes we found that small VAMP3-, VGLUT1-, and glutamate-positive SLMVs, large phogrin-positive DCGs, and lysosomes positive for markers of multivesicular bodies and late endosomes or early and recycling endosomes exist in the same astrocytes. Our results confirmed that the task of identifying a specific population of secretory organelles in astrocytes is very difficult. Moreover, studying properties of exocytosis constitutes a challenge because the cell biological basis of this process is very incompletely defined in these cells. For example, researchers have only recently started to 
understand that astrocytic exocytosis relies on multiple populations of secretory vesicles, which calls for the definition of adequate criteria to recognize the distinct populations and study them in isolation. In fact, most of the early studies of astrocyte exocytosis could not distinguish such heterogeneity as they used generic exocytosis reporters (such as synthetic fluorescent dyes). Thus, these studies did not allow an accurate description of the dynamics and properties of astrocytic secretion because they mixed contributions by more than one exocytic organelle population. As a result, the types of vesicles used in $\mathrm{Ca}^{2+}$-regulated exocytosis in astrocytes are under debate. A good experimental strategy involves trying to specifically live-stain a selected population (e.g., by transfecting the cells with a population-specific fluorescent reporter). This approach must, however, be validated by subsequent co-localization analysis with markers of the intracellular organelles, which will provide additional useful information on the nature of the stained organelles. By combining TIRF experiments and transfection of a fluorescent tool used to visualize exo/endocytosis processes in living neurons (VGLUT1-pHluorin) [28], we visualized VGLUT1positive SLMVs. We therefore characterized vesicles expressing VGLUT1 and found that they have diameter similar to that of fluorescent beads of $40 \mathrm{~nm}$, contain glutamate, and express at least one of the VAMP proteins necessary for regulated exocytosis (VAMP3).

Once confirmed that VGLUT1-pHluorin was a correct tool for studying glutamatergic SLMVs in astrocytes, we then investigated the activity of the two endogenous mediators that participate in brain intercellular chemical communication: glutamate and ATP. Glutamate and ATP are well-recognized brain signaling agents that are released in response to neuronal or glial cell stimulation and that mediate intercellular signaling $[7,51]$. Independently of their origin, both glutamate and ATP were previously shown to activate astrocytes causing intracellular $\mathrm{Ca}^{2+}$ increase followed by glutamate release $[2,52,53]$. The $\mathrm{Ca}^{2+}$-dependent exocytosis of glutamate in astrocytes is controlled by multiples mediators, all acting via receptors that belong to the GPCR super family stimulating IP3 productions ( $\mathrm{P}_{2} \mathrm{Y}_{1}$ for ATP, mGluR5 for glutamate). Stimulation of GPCR also promoted stimulation of the COX pathway of the arachidonic acid metabolism with the ensuing production and release of PGs being critical for the full efficiency of the excitation-secretion coupling in astrocytes. We in fact found that COX inhibition caused a dramatic reduction in the total number of fusion events of glutamatergic SLMVs caused by activation of both purinergic and glutamatergic receptors. By analyzing the temporal distribution of the exocytic events, we found an intriguing aspect of the mode of action of PGs. Inhibition of the PGs by either COX inhibitors or a neutralizing antibody specific for $\mathrm{PGE}_{2}$ produced a significant modification of the temporal characteristics of the exocytic burst. In particular, while the fast initial component $(0-400 \mathrm{~ms})$ was most often left intact, the second component of the burst $(500 \mathrm{~ms}-$ $1.6 \mathrm{~s}$ ) was often suppressed or significantly slowed down, suggesting that PG-mediated signaling is heavily implicated in this later, slower phase of the release. Interestingly, the rapid phase of the exocytic burst was sustained almost exclusively by "resident" vesicles, whereas the slow phase was mainly sustained by "newcomer" vesicles [9]. This duality is reminiscent of observations previously done in neurons where only readily releasable synaptic vesicles are rapidly recycled and reused [54]. As we do not know whether the "newcomer" and the "resident" vesicles represent distinct population of SLMVs, it is possible that the "newcomers" may indeed represent the same population of "resident" vesicles that undergoes a second round of exocytosis upon rapid recycling. In this context $\mathrm{PGE}_{2}$ seemed to amplify the second round of exocytosis. Since it is known that $\mathrm{PGE}_{2}$ is immediately released from astrocytes upon stimulation $[2,17]$ and that exogenous $\mathrm{PGE}_{2}$ induced rapid, $\mathrm{Ca}^{2+}$ dependent burst of glutamatergic SLMVs, it follows that a component of the burst of exocytosis in response to glutamate or ATP requires an autocrine/paracrine action of $\mathrm{PGE}_{2}$. The comparison effects of the COX blockers (about $-80 \%$ ) and $\mathrm{AbPGE}_{2}$ (about $-45 \%$ ) also indicate that extracellular $\mathrm{PGE}_{2}$ cannot be solely responsible for all the observed COXdependent events. At present we do not have a specific explanation for these differences. It is possible that other PGs could be released together with $\mathrm{PGE}_{2}$. For instance, it has been shown that intracellular $\mathrm{Ca}^{2+}$ elevations in astrocytes are known to stimulate the production of a full range of COX derivates [55] and some of them have been shown to cause $\mathrm{Ca}^{2+}$ rises and glutamate release from astrocytes $[2,56]$. The present data confirm and extend our previous finding that $\mathrm{PGE}_{2}$ participates to glutamate-dependent cellcell communication [2], suggesting a physiological function for this mediator in the intact brain. The autocrine/paracrine action of $\mathrm{PGE}_{2}$ may thus participate in the spatial control of astrocytic signal propagation. Therefore, it is possible that alterations in PGs synthesis during brain inflammations and other pathological states have a profound impact on the chemical communication in the brain. $\mathrm{PGE}_{2}$ stimulation, for instance, acts downstream of CXCL12, as well as TNF $\alpha$ pathways. Although both these pathways have been suggested to be involved in the physiological glutamate-mediated brain signalling $[5,26]$, it is likely that $\mathrm{PGE}_{2}$ synthesis will be largely amplified during inflammatory conditions, following the fate of its upstream inflammatory messengers [18]. As the whole pathway increases glutamate release from astroglial cells, much higher levels of $\mathrm{PGE}_{2}$ might represent the ultimate messenger leading to pathological increase of extracellular glutamate levels.

\section{Conflict of Interests}

The authors declare that there is no conflict of interests regarding the publication of this paper.

\section{Authors' Contribution}

Corrado Cali and Jan Lopatar contributed equally to this work. 


\section{Acknowledgments}

This work was supported by a Grant from Novartis Foundation (26077772) to P. Bezzi. The authors thank R. H. Edwards and S. Voglmaier (UCSF, USA) for providing the pHluorin construct; J. Marchaland, J. Gremion, and S. Menetrey for the experimental support.

\section{References}

[1] L. Pasti, A. Volterra, T. Pozzan, and G. Carmignoto, "Intracellular calcium oscillations in astrocytes: a highly plastic, bidirectional form of communication between neurons and astrocytes in situ," The Journal of Neuroscience, vol. 17, no. 20, pp. 7817-7830, 1997.

[2] P. Bezzi, G. Carmignoto, L. Pasti et al., "Prostaglandins stimulate calcium-dependent glutamate release in astrocytes," Nature, vol. 391, no. 6664, pp. 281-285, 1998.

[3] A. Araque, E. D. Martín, G. Perea, J. I. Arellano, and W. Buño, "Synaptically released acetylcholine evokes $\mathrm{Ca}^{2+}$ elevations in astrocytes in hippocampal slices," The Journal of Neuroscience, vol. 22, no. 7, pp. 2443-2450, 2002.

[4] G. Perea and A. Araque, "Properties of synaptically evoked astrocyte calcium signal reveal synaptic information processing by astrocytes," The Journal of Neuroscience, vol. 25, no. 9, pp. 2192-2203, 2005.

[5] M. Santello, P. Bezzi, and A. Volterra, "TNF $\alpha$ controls glutamatergic gliotransmission in the hippocampal dentate gyrus," Neuron, vol. 69, no. 5, pp. 988-1001, 2011.

[6] A. Verkhratsky, R. K. Orkand, and H. Kettenmann, "Glial calcium: homeostasis and signaling function," Physiological Reviews, vol. 78, no. 1, pp. 99-141, 1998.

[7] P. Bezzi and A. Volterra, "A neuron-glia signalling network in the active brain," Current Opinion in Neurobiology, vol. 11, no. 3, pp. 387-394, 2001.

[8] A. Volterra and J. Meldolesi, "Astrocytes, from brain glue to communication elements: the revolution continues," Nature Reviews Neuroscience, vol. 6, no. 8, pp. 626-640, 2005.

[9] J. Marchaland, C. Calì, S. M. Voglmaier et al., "Fast subplasma membrane $\mathrm{Ca}^{2+}$ transients control exo-endocytosis of synapticlike microvesicles in astrocytes," The Journal of Neuroscience, vol. 28, no. 37, pp. 9122-9132, 2008.

[10] M. T. Martineau Shi, J. Puyal, A. M. Knolhoff et al., "Storage and uptake of D-serine into astrocytic synaptic-like vesicles specify gliotransmission," The Journal of Neuroscience, vol. 33, no. 8, article U3605, pp. 3413-3423, 2013.

[11] T. Liu, L. Sun, Y. F. Xiong et al., "Calcium triggers exocytosis from two types of organelles in a single astrocyte," The Journal of Neuroscience, vol. 31, no. 29, pp. 10593-10601, 2011.

[12] C. Verderio and M. Matteoli, "ATP in neuron-glia bidirectional signalling," Brain Research Reviews, vol. 66, no. 1-2, pp. 106-114, 2011.

[13] M. Oya, T. Kitaguchi, Y. Yanagihara et al., "Vesicular nucleotide transporter is involved in ATP storage of secretory lysosomes in astrocytes," Biochemical and Biophysical Research Communications, vol. 438, no. 1, pp. 145-151, 2013.

[14] Sanzgiri, R. P. A. Araque, and P. G. Haydon, "Prostaglandin E $E_{2}$ stimulates glutamate receptor-dependent astrocyte neuromodulation in cultured hippocampal cells," Journal of Neurobiology, vol. 41, no. 2, pp. 221-229, 1999.
[15] P. Bezzi, M. Domercq, L. Brambilla et al., "CXCR4-activated astrocyte glutamate release via TNFa: amplification by microglia triggers neurotoxicity," Nature Neuroscience, vol. 4, no. 7, pp. 702-710, 2001.

[16] D. Rossi, L. Brambilla, C. F. Valori et al., "Defective tumor necrosis factor- $\alpha$-dependent control of astrocyte glutamate release in a transgenic mouse model of Alzheimer disease," The Journal of Biological Chemistry, vol. 280, no. 51, pp. 4208842096, 2005.

[17] M. Domercq, L. Brambilla, E. Pilati, J. Marchaland, A. Volterra, and P. Bezzi, "P2Y1 receptor-evoked glutamate exocytosis from astrocytes-control by tumor necrosis factor- $\alpha$ and prostaglandins," The Journal of Biological Chemistry, vol. 281, no. 41, pp. 30684-30696, 2006.

[18] D. Rossi, F. Martorana, and L. Brambilla, "Implications of gliotransmission for the pharmacotherapy of CNS disorders," CNS Drugs, vol. 25, no. 8, pp. 641-658, 2011.

[19] D. Stellwagen and R. C. Malenka, "Synaptic scaling mediated by glial TNF- $\alpha$," Nature, vol. 440, no. 7087, pp. 1054-1059, 2006.

[20] G. G. Turrigiano, "The self-tuning neuron: synaptic scaling of excitatory synapses," Cell, vol. 135, no. 3, pp. 422-435, 2008.

[21] E. C. Beattie, D. Stellwagen, W. Morishita et al., "Control of synaptic strength by glial TNF $\alpha$," Science, vol. 295, no. 5563, pp. 2282-2285, 2002.

[22] D. Stellwagen, E. C. Beattie, J. Y. Seo, and R. C. Malenka, "Differential regulation of AMPA receptor and GABA receptor trafficking by tumor necrosis factor- $\alpha$," The Journal of Neuroscience, vol. 25, no. 12, pp. 3219-3228, 2005.

[23] D. Zenisek, J. A. Steyer, M. E. Feldman, and W. Almers, "A membrane marker leaves synaptic vesicles in milliseconds after exocytosis in retinal bipolar cells," Neuron, vol. 35, no. 6, pp. 1085-1097, 2002.

[24] S. M. Voglmaier, K. Kam, H. Yang et al., "Distinct endocytic pathways control the rate and extent of synaptic vesicle protein recycling," Neuron, vol. 51, no. 1, pp. 71-84, 2006.

[25] S. Chevlet, P. Bezzi, R. Ivarsson et al., "Tomosyn-1 is involved in a post-docking event required for pancreatic $\beta$-cell exocytosis," Journal of Cell Science, vol. 119, no. 14, pp. 2912-2920, 2006.

[26] C. Calì, J. Marchaland, R. Regazzi, and P. Bezzi, "SDF 1-alpha (CXCL12) triggers glutamate exocytosis from astrocytes on a millisecond time scale: imaging analysis at the single-vesicle level with TIRF microscopy," Journal of Neuroimmunology, vol. 198, no. 1-2, pp. 82-91, 2008.

[27] A. Bergeron, P. Bezzi, and R. Regazzi, "Analysis of synapticlike microvesicle exocytosis of beta-cells using a life imaging technique," PloS ONE. In press.

[28] S. M. Voglmaier and R. H. Edwards, "Do different endocytic pathways make different synaptic vesicles?" Current Opinion in Neurobiology, vol. 17, no. 3, pp. 374-380, 2007.

[29] P. Bezzi, V. Gundersen, J. L. Galbete et al., "Astrocytes contain a vesicular compartment that is competent for regulated exocytosis of glutamate," Nature Neuroscience, vol. 7, no. 6, pp. 613-620, 2004.

[30] L. H. Bergersen and V. Gundersen, "Morphological evidence for vesicular glutamate release from astrocytes," Neuroscience, vol. 158, no. 1, pp. 260-265, 2009.

[31] S. Coco, F. Calegari, E. Pravettoni et al., "Storage and release of ATP from astrocytes in culture," The Journal of Biological Chemistry, vol. 278, no. 2, pp. 1354-1362, 2003.

[32] I. Prada, J. Marchaland, P. Podini et al., "REST/NRSF governs the expression of dense-core vesicle gliosecretion in astrocytes," The Journal of Cell Biology, vol. 193, no. 3, pp. 537-549, 2011. 
[33] P. Bezzi and A. Volterra, "Monitoring exocytosis in astrocytes with total internal reflection fluorescence microscopy," in Optical Imaging Neurons: A Laboratory Manual, Cold Spring Harbor Laboratory Press, Cold Spring Harbor, NY, USA, 2011.

[34] B. Borgonovo, E. Cocucci, G. Racchetti, P. Podini, A. Bachi, and J. Meldolesi, "Regulated exocytosis: a novel, widely expressed system," Nature Cell Biology, vol. 4, no. 12, pp. 955-962, 2002.

[35] M. Park, J. M. Salgado, L. Ostroff et al., "Plasticity-induced growth of dendritic spines by exocytic trafficking from recycling endosomes," Neuron, vol. 52, no. 5, pp. 817-830, 2006.

[36] V. Ralevic and G. Burnstock, "Receptors for purines and pyrimidines," Pharmacological Reviews, vol. 50, no. 3, pp. 413492, 1998.

[37] S. R. Fam, C. J. Gallagher, and M. W. Salter, "P2Y 1 purinoceptormediated $\mathrm{Ca}^{2+}$ signaling and $\mathrm{Ca}^{2+}$ wave propagation in dorsal spinal cord astrocytes," The Journal of Neuroscience, vol. 20, no. 8, pp. 2800-2808, 2000.

[38] A. Verkhratsky, "Calcium signalling between neurones and glia," European Journal of Neuroscience, vol. 10, pp. 322-322, 1998.

[39] N. Stella, M. Tencé, J. Glowinski, and J. Prémont, "Glutamateevoked release of arachidonic acid from mouse brain astrocytes," The Journal of Neuroscience, vol. 14, no. 2, pp. 568-575, 1994.

[40] W. L. Smith and L. J. Marnett, "Prostaglandin endoperoxide synthase: structure and catalysis," Biochimica et Biophysica Acta, vol. 1083, no. 1, pp. 1-17, 1991.

[41] V. Parpura, B. J. Baker, M. Jeras, and R. Zorec, "Regulated exocytosis in astrocytic signal integration," Neurochemistry International, vol. 57, no. 4, pp. 451-459, 2010.

[42] Q. Zhang, M. Fukuda, E. Van Bockstaele, O. Pascual, and P. G. Haydon, "Synaptotagmin IV regulates glial glutamate release," Proceedings of the National Academy of Sciences of the United States of America, vol. 101, no. 25, pp. 9441-9446, 2004.

[43] D. Crippa, U. Schenk, M. Francolini et al., "Synaptobrevin2expressing vesicles in rat astrocytes: insights into molecular characterization, dynamics and exocytosis," The Journal of Physiology, vol. 570, no. 3, pp. 567-582, 2006.

[44] T. Pangršič, M. Potokar, M. Stenovec et al., "Exocytotic release of ATP from cultured astrocytes," The Journal of Biological Chemistry, vol. 282, no. 39, pp. 28749-28758, 2007.

[45] C. M. Anderson and M. Nedergaard, "Astrocyte-mediated control of cerebral microcirculation," Trends in Neurosciences, vol. 26, no. 7, pp. 340-344, 2003.

[46] P. G. Haydon and G. Carmignoto, "Astrocyte control of synaptic transmission and neurovascular coupling," Physiological Reviews, vol. 86, no. 3, pp. 1009-1031, 2006.

[47] P. Jourdain, L. H. Bergersen, K. Bhaukaurally et al., "Glutamate exocytosis from astrocytes controls synaptic strength," Nature Neuroscience, vol. 10, no. 3, pp. 331-339, 2007.

[48] P. Ramamoorthy and M. D. Whim, "Trafficking and fusion of neuropeptide Y-containing dense-core granules in astrocytes," The Journal of Neuroscience, vol. 28, no. 51, pp. 13815-13827, 2008.

[49] J. K. Jaiswal, M. Fix, T. Takano, M. Nedergaard, and S. M. Simon, "Resolving vesicle fusion from lysis to monitor calciumtriggered lysosomal exocytosis in astrocytes," Proceedings of the National Academy of Sciences of the United States of America, vol. 104, no. 35, pp. 14151-14156, 2007.

[50] Z. J. Zhang, G. Chen, W. Zhou et al., "Regulated ATP release from astrocytes through lysosome exocytosis," Nature Cell Biology, vol. 9, no. 8, article U115, pp. 945-953, 2007.
[51] R. D. Fields and B. Stevens, "ATP: an extracellular signaling molecule between neurons and glia," Trends in Neurosciences, vol. 23, no. 12, pp. 625-633, 2000.

[52] M. L. Cotrina, J. H.-C. Lin, A. Alves-Rodrigues et al., "Connexins regulate calcium signaling by controlling ATP release," Proceedings of the National Academy of Sciences of the United States of America, vol. 95, no. 26, pp. 15735-15740, 1998.

[53] J. Xu, H. Peng, N. Kang et al., "Glutamate-induced exocytosis of glutamate from astrocytes," The Journal of Biological Chemistry, vol. 282, no. 33, pp. 24185-24197, 2007.

[54] N. C. Harata, A. M. Aravanis, and R. W. Tsien, "Kiss-andrun and full-collapse fusion as modes of exo-endocytosis in neurosecretion," Journal of Neurochemistry, vol. 97, no. 6, pp. 1546-1570, 2006.

[55] K. Oomagari, B. Buisson, A. Dumuis, J. Bockaert, and J.-P. Pin, "Effect of glutamate and ionomycin on the release of arachidonic acid, prostaglandins and HETEs from cultured neurons and astrocytes," European Journal of Neuroscience, vol. 3, no. 10, pp. 928-939, 1991.

[56] J. Kitanaka, K. Takuma, K. Kondo, and A. Baba, "Prostanoid receptor-mediated calcium signaling in cultured rat astrocytes," Japanese Journal of Pharmacology, vol. 71, no. 1, pp. 85-87, 1996. 

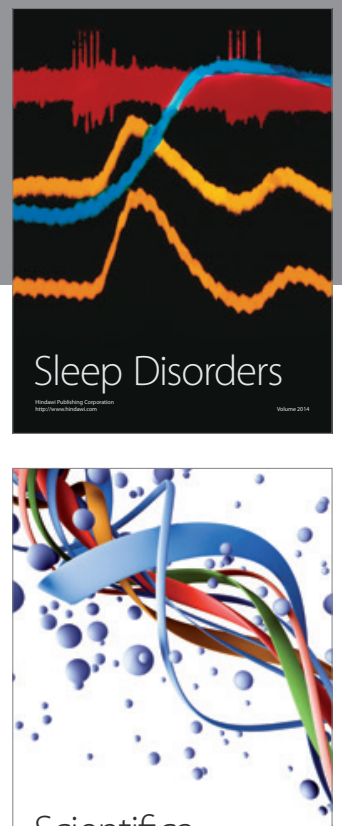

Scientifica
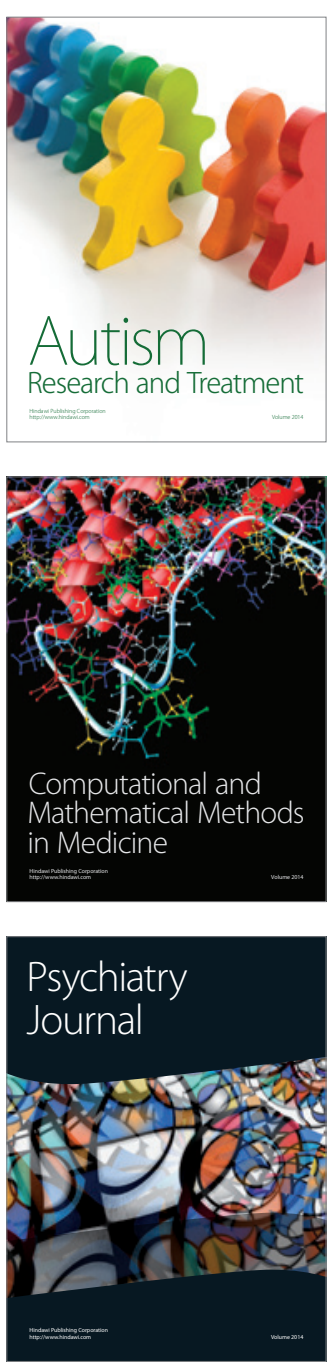
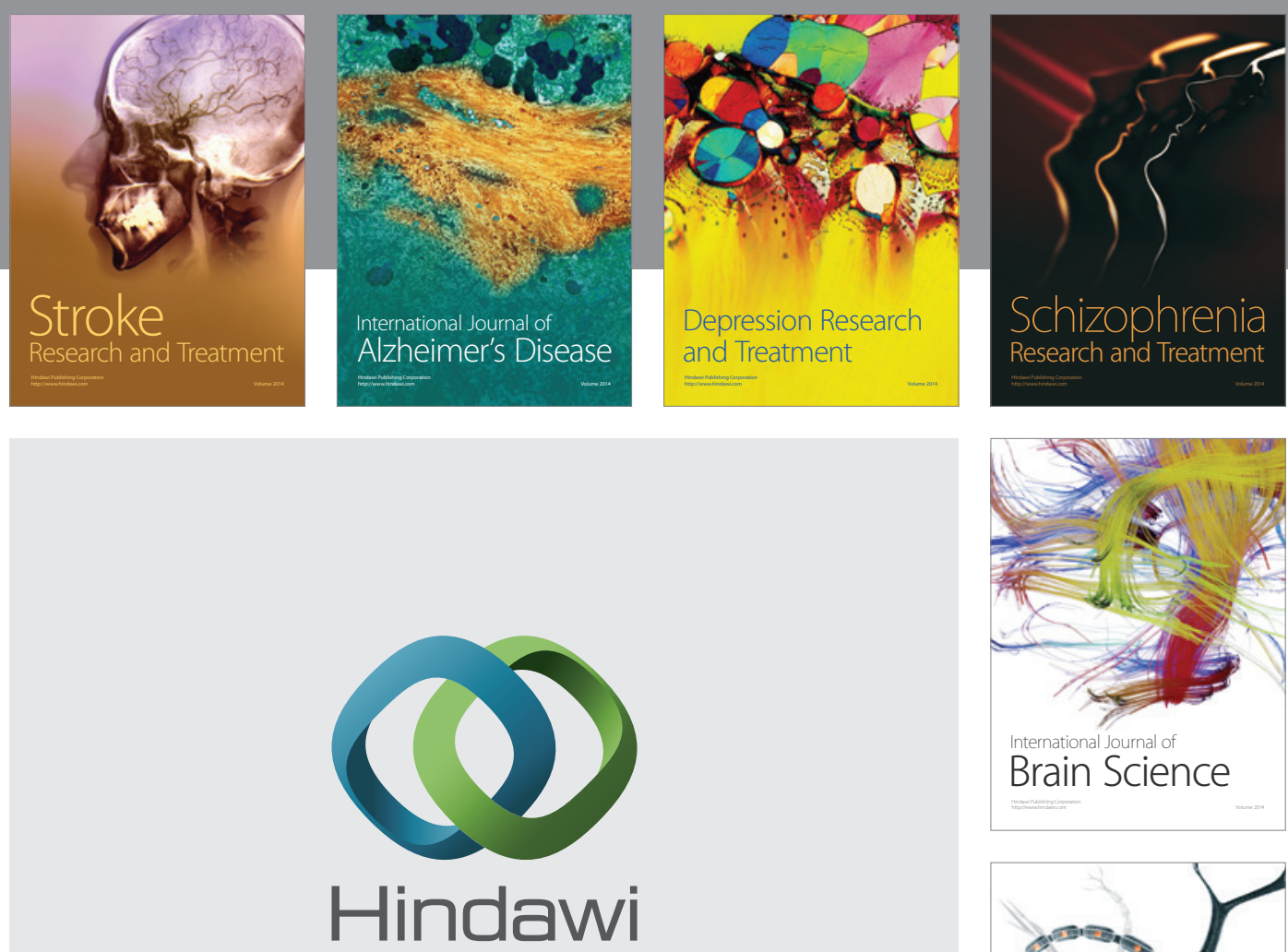

Submit your manuscripts at

http://www.hindawi.com
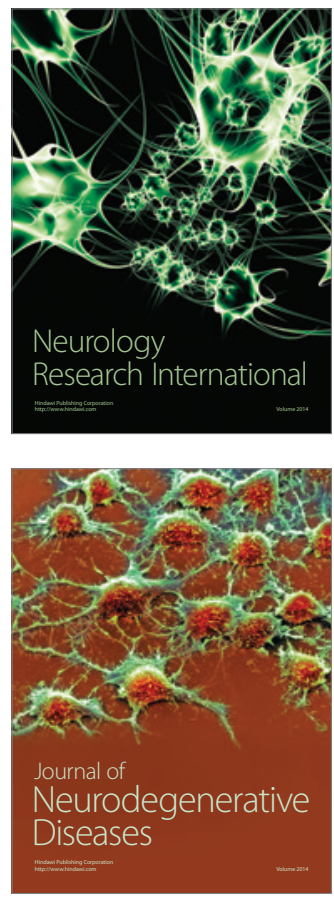

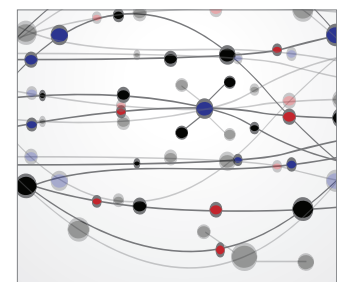

The Scientific World Journal
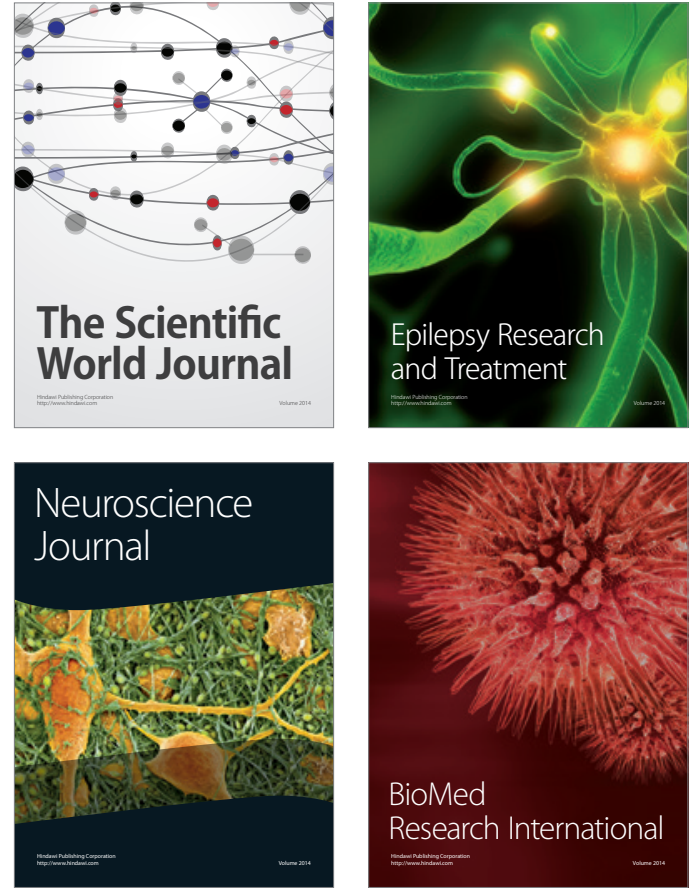

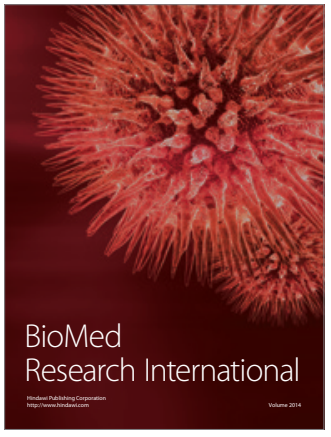

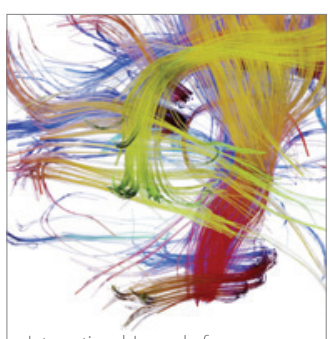

Brain Science

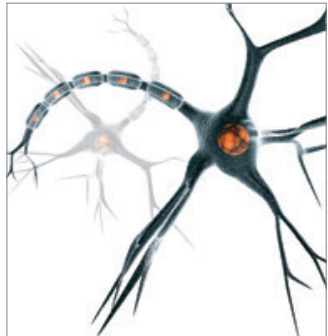

Neural Plasticity
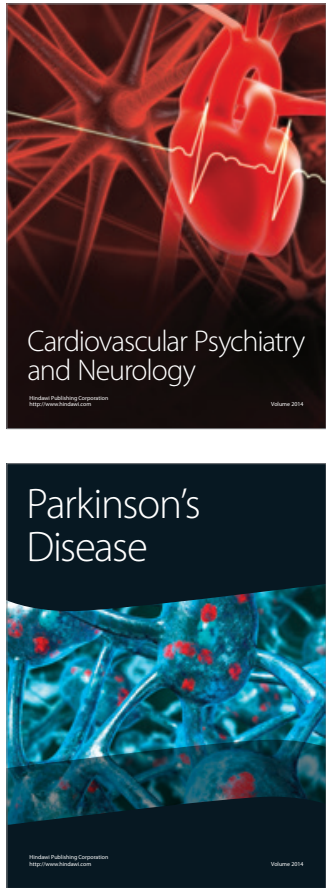